\title{
Interhospital transfer status for spinal metastasis patients in the United States is associated with more severe clinical presentations and higher rates of inpatient complications
}

\author{
Rafael De la Garza Ramos, MD, ${ }^{2}$ Christine Park, BS, ${ }^{1}$ Edwin McCray, BS, ${ }^{1}$ Meghan Price, BS, ${ }^{1}$ \\ Timothy Y. Wang, MD, ${ }^{1}$ Tara Dalton, MSc, ${ }^{1}$ César Baëta, MP, MMCi, ${ }^{1}$ Melissa M. Erickson, MD, ${ }^{3}$ \\ Norah Foster, MD, ${ }^{4}$ Zach Pennington, BS, ${ }^{5}$ John H. Shin, MD, ${ }^{6}$ Daniel M. Sciubba, MD, ${ }^{5}$ \\ Khoi D. Than, MD, Isaac O. Karikari, MD, ${ }^{1}$ Christopher I. Shaffrey, MD, ${ }^{1}$ \\ Muhammad M. Abd-El-Barr, MD, PhD, ${ }^{1}$ Reza Yassari, MD, ${ }^{2}$ and C. Rory Goodwin, MD, PhD ${ }^{1}$
}

Departments of ${ }^{1}$ Neurosurgery and ${ }^{3}$ Orthopedic Surgery, Spine Division, Duke University Medical Center, Durham, North Carolina; ${ }^{2}$ Department of Neurosurgery, Montefiore Medical Center, New York, New York; ${ }^{4}$ Premier Health Orthopedics, Centerville, Ohio; ${ }^{5}$ Department of Neurosurgery, Johns Hopkins School of Medicine, Baltimore, Maryland; and ${ }^{6}$ Department of Neurosurgery, Massachusetts General Hospital, Harvard Medical School, Boston, Massachusetts

\begin{abstract}
OBJECTIVE In patients with metastatic spinal disease (MSD), interhospital transfer can potentially impact clinical outcomes as the possible benefits of transferring a patient to a higher level of care must be weighed against the negative effects associated with potential delays in treatment. While the association of clinical outcomes and transfer status has been examined in other specialties, the relationship between transfer status, complications, and risk of mortality in patients with MSD has yet to be explored. The purpose of this study was to examine the impact of transfer status on inhospital mortality and clinical outcomes in patients diagnosed with MSD.

METHODS The National (Nationwide) Inpatient Sample (NIS) database was retrospectively queried for adult patients diagnosed with vertebral pathological fracture and/or spinal cord compression in the setting of metastatic disease between 2012 and 2014. Demographics, baseline characteristics (e.g., metastatic spinal cord compression [MSCC] and paralysis), comorbidities, type of intervention, and relevant patient outcomes were controlled in a multivariable logistic regression model to analyze the association of transfer status with patient outcomes.
\end{abstract}

RESULTS Within the 10,360 patients meeting the inclusion and exclusion criteria, higher rates of MSCC $(50.2 \%$ vs $35.9 \%, p<0.001)$ and paralysis ( $17.3 \%$ vs $8.4 \%, p<0.001)$ were observed in patients transferred between hospitals compared to those directly admitted. In univariable analysis, a higher percentage of transferred patients underwent surgical intervention ( $p<0.001$ ) when compared with directly admitted patients. After controlling for significant covariates and surgical intervention, transferred patients were more likely to develop in-hospital complications (OR 1.34, 95\% Cl 1.18-1.52, p< 0.001 ), experience prolonged length of stay (OR 1.33, 95\% Cl 1.16-1.52, $p<0.001)$, and have a discharge disposition other than home (OR 1.70, 95\% Cl 1.46-1.98, p < 0.001), with no significant difference in inpatient mortality rates.

CONCLUSIONS Patients with MSD who were transferred between hospitals demonstrated more severe clinical presentations and higher rates of inpatient complications compared to directly admitted patients, despite demonstrating no difference in in-hospital mortality rates.

https://thejns.org/doi/abs/10.3171/2021.2.FOCUS201085

KEYWORDS mortality; patient outcomes; spinal metastasis; transfer status; spinal cord compression; paralysis; surgery; complications

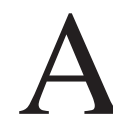
s cancer treatments continue to improve, oncology patients are living longer with an increased incidence of metastatic disease. ${ }^{1,2}$ The spinal column is the most common site of osseous metastatic disease and can be associated with spinal cord compression, pathological fractures, and/or pain. ${ }^{3-11}$ Spinal cord compression can result in weakness, paresthesias, urinary/bowel dysfunction, and paralysis. Patients with metastatic spinal disease

ABBREVIATIONS CCI = Charlson Comorbidity Index; CCS = Clinical Classification Software; ICD-9 = International Classification of Diseases, 9th Revision; MSCC = metastatic spinal cord compression; MSD = metastatic spinal disease; NIS = National (Nationwide) Inpatient Sample.

SUBMITTED December 22, 2020. ACCEPTED February 16, 2021.

INCLUDE WHEN CITING DOI: 10.3171/2021.2.FOCUS201085. 


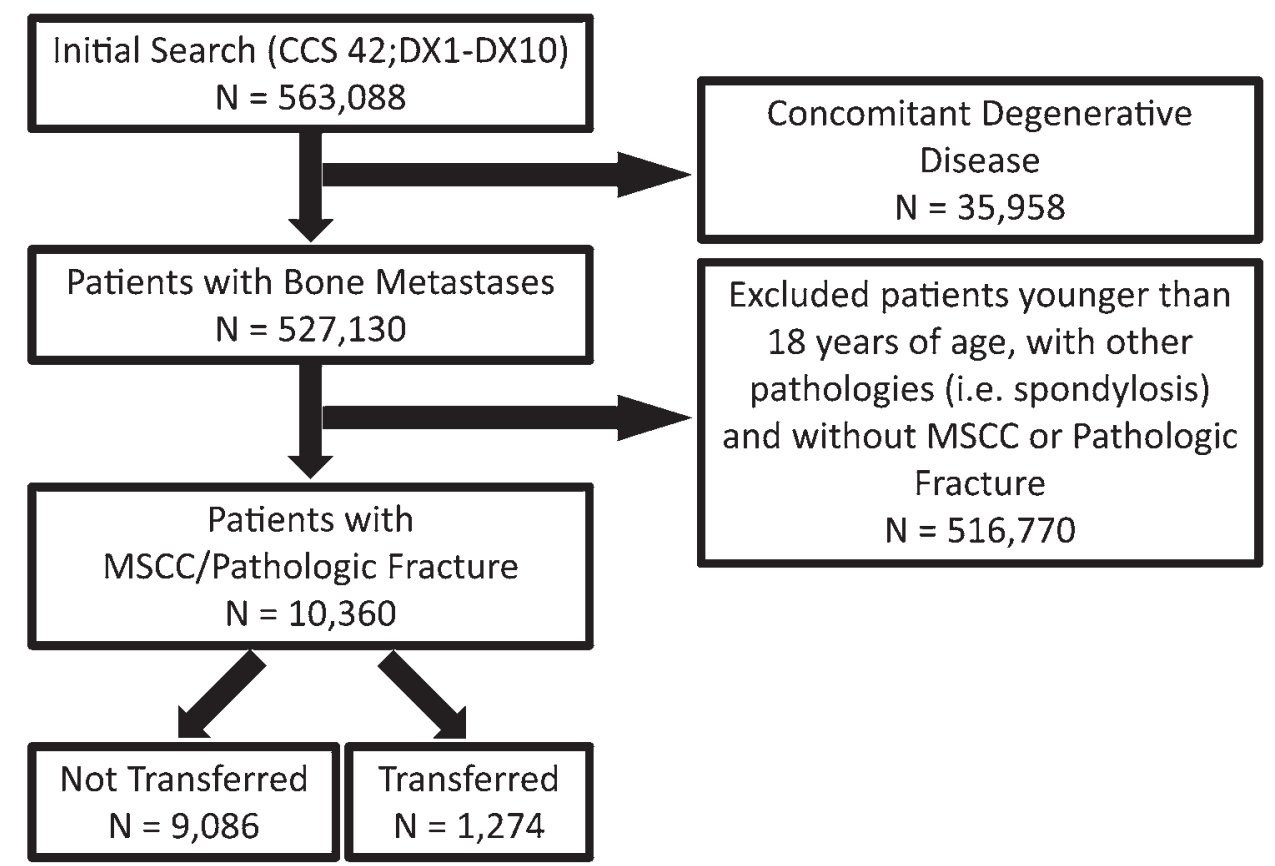

FIG. 1. CONSORT diagram of a selection of the patient cohort.

(MSD) often require multidisciplinary management with surgical intervention, chemotherapy, radiation, and systemic therapies. ${ }^{12}$ The occurrence of an acute decline in neurological function can result in a greater likelihood of nonelective admissions and interhospital transfers in this patient population. ${ }^{13}$ Furthermore, the complexity and severity of clinical presentation are shown to be associated with postoperative complications and worse prognosis. ${ }^{14}$

Hospitals lacking resources or expertise to effectively manage a given patient may request an interhospital transfer to another tertiary care facility, either through provider-to-provider communication as an inpatient or under the Emergency Medical Treatment and Active Labor Act. ${ }^{15}$ While there are no official guidelines or criteria defining a hospital's resources, expertise, or clinical criteria for transfer, this system aims to transfer patients in need of a higher level of care to hospitals capable of delivering said care. The decision to transfer must therefore weigh the benefits of transfer to a higher level of care against the downsides of a delay in care. This cost-benefit analysis has been explored in other realms of neurosurgery, notably in patients with general or neurological emergencies. ${ }^{16-20}$ Numerous studies have demonstrated that neurological presentation, systemic burden of disease, and demographic factors, including age at admission, are factors in determining prognosis and clinical outcomes. ${ }^{21-24}$ However, no study has examined the relationship between transfer status and outcomes specifically in patients with MSD.

In this study, we compare the in-hospital mortality and clinical outcomes of patients with MSD who underwent interhospital transfer to those who were directly admitted to the hospital. Specifically, we examine association of transfer status with clinical presentation, type of inter- vention, in-hospital complications, length of stay, rate of nonroutine discharge, and in-hospital mortality.

\section{Methods}

\section{Study Design and Setting}

The National (Nationwide) Inpatient Sample (NIS) database, which is a collection of inpatient hospitalization data drawn from more than 4500 hospitals within the continental United States, was retrospectively queried for this analysis. The database contains information related to hospital admission, including patient demographics and comorbidities, hospital course, discharge disposition, access to care, and cost of care..$^{20}$ The study period was between January 1, 2012, and December 31, 2014. Transfer status was defined as either direct hospital admission or transfer from an outside facility.

\section{Participants}

Adult patients (aged 18 years or older) with a diagnosis of vertebral pathological fracture and/or spinal cord compression in the setting of a secondary malignancy (i.e., metastatic disease) were included in our analysis. Further details on the inclusion and exclusion criteria can be found in the CONSORT diagram (Fig. 1).

\section{Variables}

International Classification of Diseases, 9th Revision (ICD-9) and Clinical Classification Software (CCS) codes that were used for identifying diagnoses and procedures are summarized in Table 1. Demographics considered were age at the time of admission, sex, insurance status, median household income (by zip code), admitting hospi- 
tal characteristics (size, region, and type), smoking status, and primary tumor type. Relevant baseline characteristics included Charlson Comorbidity Index (CCI) score, presence of metastatic spinal cord compression (MSCC; ICD9 code 336.3), vertebral pathological fracture, paralysis (ICD-9 code 344.1), and visceral metastasis. Outcome measures included in-hospital mortality, in-hospital complication, type of intervention (surgery, biopsy, radiotherapy, and chemotherapy), prolonged hospital length of stay ( $>$ 75th percentile), and nonroutine discharge (discharge disposition other than home, such as acute care hospital, rehabilitation facility, or skilled nursing facility).

\section{Statistical Considerations}

All analyses were performed in Stata/SE 12 (StataCorp LLC). Stata survey commands were used to analyze the study sample. All data were summarized using descriptive statistics. Groups stratified by transfer status were compared via analyses of variance and chi-square tests. In the multivariable logistic regression, we controlled for the following covariates to identify the effect of transfer status on patient outcomes: age at the time of admission, sex, insurance status, income, admitting hospital characteristics, CCI score, smoking status, primary tumor type, and all baseline characteristics (MSCC, vertebral pathological fracture, paralysis, and visceral metastasis). Statistical significance was defined as $\mathrm{p}<0.05$.

\section{Results}

An initial cohort of 563,088 adult patients with a diagnosis of secondary malignancy between 2012 and 2014 were identified in the NIS database. Of these, 527,130 were found to have osseous metastasis without a concomitant degenerative disease diagnosis. After applying all inclusion and exclusion criteria, a cohort of 10,360 patients were included in the analyses of demographics and clinical outcomes (Fig. 1). Application of discharge weights (roughly a fivefold multiplication, given NIS is a $20 \%$ sample database) would imply a sample size of 51,800 patients.

\section{Patient Demographics}

Patient demographics are summarized for the 10,360 patients in Table 2. In our sample, 9086 (87.7\%) patients were directly admitted to the hospital, while $1274(12.3 \%)$ patients were transferred from another institution. The mean age at the time of admission was 64.3 years for both groups. A higher percentage of patients in the transfer cohort were male compared with those who were directly admitted (56.6\% vs $51.6 \%, \mathrm{p}<0.001)$. A greater number of patients who were transferred were ultimately admitted to an urban teaching hospital $(80.1 \%$ vs $68.6 \%, \mathrm{p}<0.001)$ or to a large hospital $(72.1 \%$ vs $65.7 \%$, p < 0.001$)$ compared with those who were directly admitted. The median household income also differed significantly between the 2 groups, with transferred patients more commonly living in zip codes with median incomes in the 1st or 2nd quartiles. Aside from these 3 features, the patient cohorts were similar in most demographic characteristics (e.g., insurance status and smoking status).
TABLE 1. Codes for collected data

\begin{tabular}{|c|c|c|}
\hline Diagnosis/Procedure & ICD-9 & $\operatorname{ccs}$ \\
\hline \multicolumn{3}{|l|}{ Spinal metastasis } \\
\hline Secondary malignancy & & 42 \\
\hline Metastasis to bone & 198.5 & \\
\hline \multicolumn{3}{|l|}{ Types of intervention } \\
\hline Spinal decompression & $\begin{array}{c}\text { 03.01, } 03.09, \text { 03.4 } \\
03.53\end{array}$ & \\
\hline Fusion & $81.00-81.08,81.61$ & \\
\hline Biopsy & & $37,38,76,83,165$ \\
\hline Radiotherapy & & 211 \\
\hline Chemotherapy & & 224 \\
\hline \multicolumn{3}{|l|}{ In-hospital complications } \\
\hline $\begin{array}{l}\text { Neurological } \\
\text { complications }\end{array}$ & $997.00-997.09$ & \\
\hline Pneumonia & & 122 \\
\hline $\begin{array}{l}\text { Other respiratory } \\
\text { complications }\end{array}$ & $\begin{array}{c}518.5,518.81,518.84 \\
997.3\end{array}$ & \\
\hline $\begin{array}{l}\text { Venous } \\
\text { thromboembolism }\end{array}$ & $\begin{array}{c}415.11-415.19 \\
453.40-453.42 \\
453.8,453.9\end{array}$ & \\
\hline Cardiac complications & 997.1 & 410 \\
\hline $\begin{array}{l}\text { Urinary/renal } \\
\text { complications }\end{array}$ & $584.5,584.9,997.5$ & \\
\hline $\begin{array}{l}\text { Gastrointestinal } \\
\text { complications }\end{array}$ & $008.45,560.1,997.4$ & \\
\hline Urinary tract infection & $595.0,595.9,599.0$ & \\
\hline Sepsis & & 2 \\
\hline Decubitus ulcers & 707.01-707.09 & \\
\hline
\end{tabular}

\section{Clinical Presentation}

A greater number of patients who were transferred presented with MSCC (50.2\% vs $35.9 \%$, p < 0.001$)$ and paralysis $(17.3 \%$ vs $8.4 \%, \mathrm{p}<0.001)$. On the other hand, a lower number of the transferred patients presented with vertebral pathological fractures $(67.1 \%$ vs $75.5 \%, \mathrm{p}<0.001)$ and visceral metastases $(39.0 \%$ vs $42.0 \%, \mathrm{p}<0.05)$ compared with those who were directly admitted. Furthermore, there was a statistically significant difference in primary tumor type between the cohorts, whereas the CCI score did not differ significantly (Table 2).

\section{Univariable Analysis of Hospital Course and Clinical Outcomes}

In terms of the type of intervention, a higher proportion of patients who were transferred underwent surgery compared with those who were directly admitted $(21.2 \%$ vs $14.8 \%, \mathrm{p}<0.001$ ) (Fig. 2). The number of patients who received chemotherapy or radiotherapy did not differ significantly between the 2 cohorts. In-hospital mortality rates also did not differ between the 2 groups $(7.4 \%$ vs $7.0 \%$ for transfer and direct admission, respectively; $\mathrm{p}=$ 0.529) (Fig. 3A). However, more patients who were transferred experienced prolonged length of stay in the hospital (31.1\% vs $22.9 \%$, p < 0.001$)$, nonroutine discharges $(79.6 \%$ 
TABLE 2. Demographics and baseline characteristics of patients stratified by transfer status

\begin{tabular}{|c|c|c|c|c|}
\hline Variable & All Patients & Direct & Transferred & $\mathrm{p}$ Value \\
\hline No. of patients & 10,360 & $9,086(87.7)$ & $1,274(12.3)$ & \\
\hline \multicolumn{5}{|l|}{ Demographics } \\
\hline Mean age, yrs (SD) & $64.3(13.3)$ & $64.3(13.3)$ & $64.3(13.2)$ & $0.959^{*}$ \\
\hline Age $>65$ yrs & 46.9 & 46.7 & 47.8 & 0.467 \\
\hline Male sex & 52.2 & 51.6 & 56.6 & $<0.001^{*}$ \\
\hline Insurance & & & & $0.200^{*}$ \\
\hline Medicare & 50.5 & 50.5 & 50.6 & \\
\hline Medicaid & 13.6 & 13.7 & 12.2 & \\
\hline Private & 29.9 & 29.9 & 30.0 & \\
\hline Other/unknown & 6.1 & 5.9 & 7.2 & \\
\hline Income quartile & & & & $<0.001^{*}$ \\
\hline $1 \mathrm{st}$ & 26.4 & 25.7 & 31.0 & \\
\hline 2nd & 23.5 & 23.3 & 25.7 & \\
\hline $3 r d$ & 24.8 & 25.1 & 22.3 & \\
\hline 4th & 25.3 & 25.9 & 21.0 & \\
\hline Urban teaching hospital & 70.0 & 68.6 & 80.1 & $<0.001^{*}$ \\
\hline Large hospital size & 66.5 & 65.7 & 72.1 & $<0.001^{*}$ \\
\hline Smoking & 35.7 & 35.6 & 37.0 & $0.326^{*}$ \\
\hline Primary tumor type & & & & $<0.001^{*}$ \\
\hline Lung & 26.7 & 26.3 & 29.4 & \\
\hline Breast & 19.4 & 19.9 & 15.4 & \\
\hline Prostate & 15.2 & 14.9 & 17.6 & \\
\hline Colon & 5.1 & 5.1 & 4.8 & \\
\hline Kidney & 7.1 & 7.1 & 7.6 & \\
\hline Other/unspecified & 26.5 & 26.7 & 25.3 & \\
\hline \multicolumn{5}{|l|}{ Baseline characteristics } \\
\hline Mean CCl (SD) & $6.7(1.1)$ & $6.7(1.1)$ & $6.7(1.1)$ & $0.390^{*}$ \\
\hline MSCC & 37.7 & 35.9 & 50.2 & $<0.001^{*}$ \\
\hline Vertebral pathological fracture & 74.4 & 75.5 & 67.1 & $<0.001^{*}$ \\
\hline Paralysis & 9.5 & 8.4 & 17.3 & $<0.001^{*}$ \\
\hline Visceral metastasis & 41.7 & 42.0 & 39.0 & $0.039^{*}$ \\
\hline
\end{tabular}

vs $68.1 \%, p<0.001$ ), and in-hospital complication rates (49.6\% vs $42.2 \%, p<0.001)$ compared with those who were directly admitted (Fig. 3A). Specifically, patients who were transferred more frequently developed pulmonary complications $(9.3 \%$ vs $7.6 \%, p<0.05)$, deep venous thrombosis $(6.7 \%$ vs $3.8 \%, \mathrm{p}<0.001)$, and gastrointestinal complications $(5.1 \%$ vs $2.9 \%, \mathrm{p}<0.001)$ (Fig. 3B).

\section{Multivariable Analysis of Outcomes Stratified by Transfer Status}

After controlling for the covariate in the multivariable logistic regression analysis, the results of the multivariable analysis were consistent with the univariable analysis. Patient transfer status was found to be an independent predictor for surgical intervention, with patients who were transferred being more likely to undergo surgery (OR $1.26,95 \%$ CI $1.08-1.49, \mathrm{p}<0.05)$. When controlling for both covariates and surgical intervention, transferred patients were also more likely to develop in-hospital complications (OR 1.34, 95\% CI 1.18-1.52, p <0.001), experience prolonged length of stay (OR 1.33, 95\% CI 1.16-1.52, p < 0.001 ), and have nonroutine discharge (OR 1.70, 95\% CI $1.46-1.98, \mathrm{p}<0.001)$. There was no significant difference in in-hospital mortality between those directly admitted and those who were transferred (OR 1.05, 95\% CI $0.83-$ $1.34, \mathrm{p}=0.662)($ Table 3$)$.

\section{Discussion}

Metastatic spinal disease (MSD) is associated with a wide array of symptoms that can necessitate multidisciplinary management and increased resource utilization. ${ }^{12,25}$ Hospitals lacking sufficient resources and/or expertise to effectively manage these patients rely on inter- 


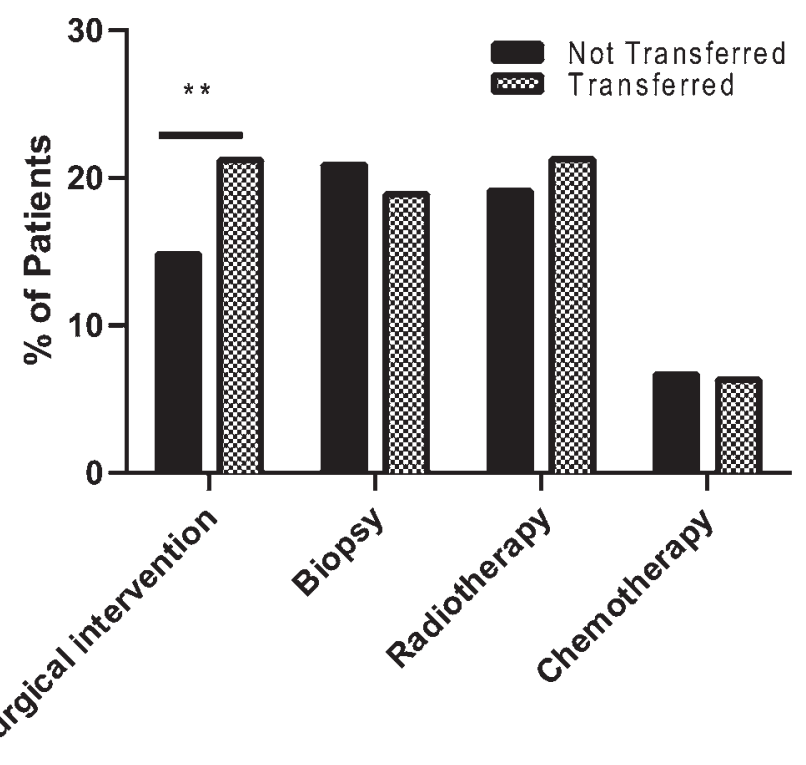

FIG. 2. Differences in intervention stratified by patient transfer status $\left({ }^{* *} p<0.01\right)$.

hospital transfer to convey patients to centers capable of providing a higher level of care..$^{15}$ In this study, we evaluated the association of transfer status, in-hospital mortality, and short-term clinical outcomes in patients diagnosed with MSD. Our results demonstrate that although patients in the transferred cohort more commonly presented with MSCC and paralysis, there was no significant difference in mortality rates between patients directly admitted to the hospital and those transferred. For both univariable and multivariable analyses, transferred patients were more likely to undergo surgical intervention and have higher rates of in-hospital complications, prolonged length of stay, and nonroutine discharge.

Similar to other studies examining outcomes for transferred patients, patients with MSD who were transferred were more likely to have a more severe clinical presentation (i.e., MSCC and paralysis) and need a higher level of care (more commonly admitted to urban teaching and/ or tertiary medical centers) than those who were directly admitted. ${ }^{26}$ In spite of the more aggressive disease at presentation, transferred patients were also more likely to undergo surgical intervention, suggesting the impetus to transfer in many cases may be to move patients to hospitals that offer specialized treatments, such as surgical intervention. ${ }^{27,28}$ Along these lines, Kamat et al. found that cancer patients were commonly transferred to oncology centers for interventional procedures but were seldom transferred for treatment in the critical care unit without a plan for a procedure..$^{28}$ In our study, we likewise found that, while transferred patients more frequently underwent surgical intervention, rates of more conservative therapies (i.e., radiotherapy and chemotherapy) were similar in transferred and direct-admission patients. Given the retrospective nature of our study, we cannot establish the causality of this relationship, but the differences are nevertheless intriguing and warrant further investigation.

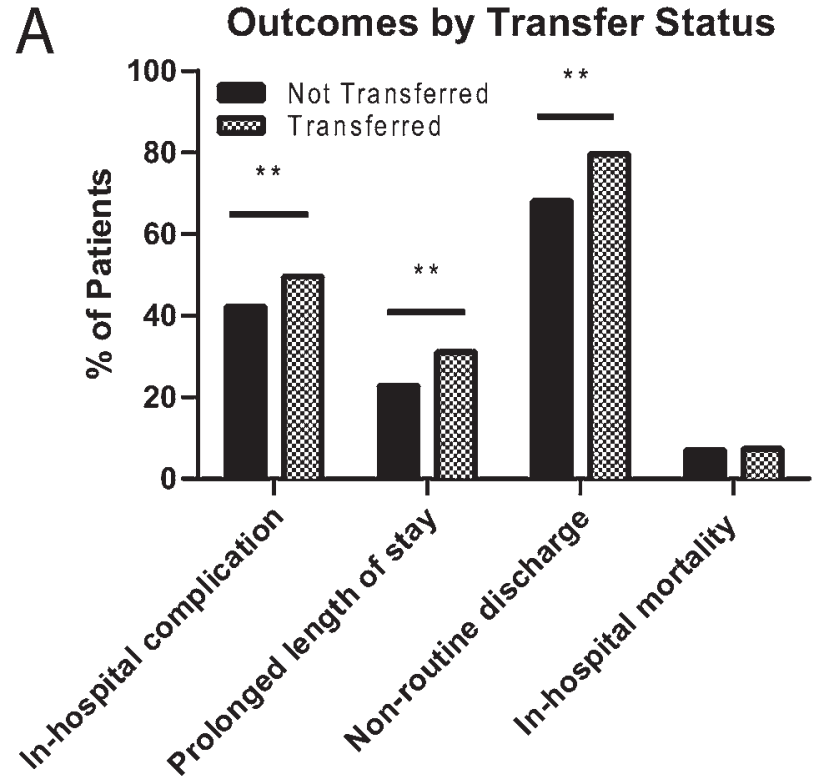

B Type of Complication by Transfer Status

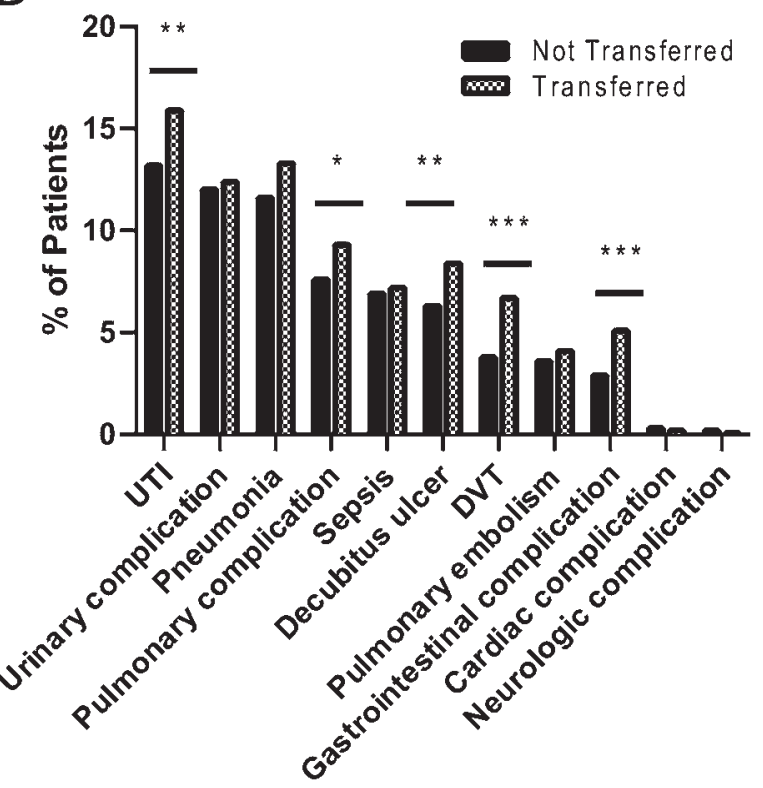

FIG. 3. A: Differences in in-hospital mortality and clinical outcomes stratified by patient transfer status. B: Types of in-hospital complication stratified by patient transfer status $\left({ }^{*} p<0.05,{ }^{* *} p<0.01,{ }^{* *} p<0.001\right)$. DVT = deep venous thrombosis; UTI = urinary tract infection.

\section{In-Hospital Mortality}

Studies have shown a correlation between transfer status and mortality rates across different medical and surgical disciplines. Hernandez-Boussard et al. found that transferred patients were twice as likely to die than those directly admitted after risk adjustments, regardless of medical discipline. ${ }^{29}$ Moreover, Sokol-Hessner et al. reported that patients transferred to the general medicine service had higher inpatient mortality rates than those admitted directly from the emergency department, sug- 
TABLE 3. Multivariable associations between transfer status and patient outcomes

\begin{tabular}{|c|c|c|}
\hline Patient Outcome & Direct & Transferred \\
\hline \multicolumn{3}{|l|}{ Surgical intervention* } \\
\hline OR & 1.00 & 1.26 \\
\hline $95 \% \mathrm{Cl}$ & & $1.08-1.49$ \\
\hline$p$ value & & 0.010 \\
\hline \multicolumn{3}{|c|}{ In-hospital complication† } \\
\hline OR & 1.00 & 1.34 \\
\hline $95 \% \mathrm{Cl}$ & & $1.18-1.52$ \\
\hline$p$ value & & $<0.001$ \\
\hline \multicolumn{3}{|c|}{ Prolonged length of stay $\dagger$} \\
\hline OR & 1.00 & 1.33 \\
\hline $95 \% \mathrm{Cl}$ & & $1.16-1.52$ \\
\hline$p$ value & & $<0.001$ \\
\hline \multicolumn{3}{|l|}{ Nonroutine discharge $\dagger$} \\
\hline OR & 1.00 & 1.70 \\
\hline $95 \% \mathrm{Cl}$ & & $1.46-1.98$ \\
\hline$p$ value & & $<0.001$ \\
\hline \multicolumn{3}{|l|}{ In-hospital mortality $\dagger$} \\
\hline OR & 1.00 & 1.05 \\
\hline $95 \% \mathrm{Cl}$ & & $0.83-1.34$ \\
\hline$p$ value & & 0.650 \\
\hline
\end{tabular}

* Covariates that were controlled included patient age, sex, insurance status, teaching hospital, hospital size, CCl, smoking, tumor type, MSCC, pathological fracture, paralysis, and visceral metastasis.

† Surgical intervention was controlled for in addition to covariates.

gesting that interhospital transfer could be a factor associated with poor outcomes. ${ }^{27}$ Despite this, we found that the lack of association between transfer status and inpatient mortality is consistent with prior findings from the neurological trauma literature. In patients with intracerebral hemorrhage, Vahidy et al. observed no difference in functional outcomes and mortality between direct-admit and transferred patients. ${ }^{30}$ Naval and Carhuapoma also saw no differences in in-hospital mortality rates between the patients with intracerebral hemorrhage who were directly admitted or transferred. ${ }^{31}$ Holland et al. showed that the mortality rate in transferred patients with spinal cord injury decreased in their study period, while the frequency of surgical management before transfer increased..$^{32}$

Multiple studies have identified predictors of increased length of stay and complications in MSD patients. For example, factors associated with frailty and disability, which portend a higher risk for adverse health outcomes and/ or reduced functional status, are shown to be independently associated with poorer outcomes. ${ }^{33-35}$ Additionally, patient-specific factors (e.g., nutrition status), operative factors (e.g., number of operated vertebral levels), postoperative complications, and tumor-specific factors (e.g., primary tumor type) are also shown to impact length of stay and in-hospital complications in MSD patients. ${ }^{36-39} \mathrm{In}$ our study, transferred patients were more likely to develop in-hospital complications, particularly pulmonary complications, deep venous thrombosis, and gastrointestinal complications. The transferred cohort had a more severe clinical presentation and evidence of more advanced systemic disease, which was most likely associated with the higher rate of medical complications, prolonged length of stay, and nonroutine discharge in this group. Determining whether the clinical decision to transfer these patients was based on the increased complexity of this patient population at baseline or the patient's specific need for a surgical intervention is beyond the scope of this paper. However, we assumed that transfers were placed to pair patients with facilities able to accommodate this complexity and provide increased resources to appropriately care for these patients. Although no prior study has evaluated the impact of hospital transfer status in MSD patients, we acknowledge that there may be an interaction of these perioperative factors with transfer status and that these may influence the observed outcomes. Additionally, while we were not able to evaluate whether the length of time prior to transfer impacted patient outcomes and complication rates, this will be important to address with future studies. Specifically, understanding the impact of treatment delay would be critical for identifying transfer populations at higher risk for complications and more likely to require surgical intervention.

\section{Limitations}

There are several limitations associated with this study. Due to the retrospective nature of this study using a large national database, diagnosis and procedural data were dependent on the accuracy of documentation and coding. Additionally, the NIS database has undergone several revisions and data structure modifications over the years, which can negatively affect coding consistency and completeness of the data recorded. Thus, the variability of data and lack of specificity associated with the ICD-9 and CCS codes were unavoidable. Furthermore, no causality can be inferred from the results due to the retrospective nature of the registry. Because NIS primarily collects inpatient data, no further follow-up analysis could be done on individual patients. For this reason, we were not able to assess whether transfer status affected postdischarge outcomes. The data set did not distinguish the trauma center levels of the hospitals involved, which hindered our ability to assess the impact of trauma center level on mortality and patient outcomes. Finally, the lack of granularity of the data prevents further analysis on the effect of admitting hospital characteristics in transferred patients, and whether time in transit and subsequently the time to treatment impacted the interventions received and outcomes observed in the study. Despite these limitations, this large study is the first to explore the effect of interhospital transfer in patients with MSD. Our data can serve as the foundation for future investigations.

\section{Conclusions}

In patients diagnosed with MSD, those who were transferred between hospitals had worse baseline characteristics, were more likely to undergo surgical intervention, and experienced more complications relative to those who were directly admitted to a treating hospital. Nevertheless, 
mortality rates in both cohorts were similar, which suggests that the act of transferring a patient to a higher level of care may not subject them to undue risk. Further investigations into this relationship are necessary to identify whether this relationship remains independent of the time to treatment.

\section{References}

1. Hayat MJ, Howlader N, Reichman ME, Edwards BK. Cancer statistics, trends, and multiple primary cancer analyses from the Surveillance, Epidemiology, and End Results (SEER) Program. Oncologist. 2007;12(1):20-37.

2. Dillekås H, Rogers MS, Straume O. Are $90 \%$ of deaths from cancer caused by metastases? Cancer Med. 2019;8(12):55745576.

3. Macedo F, Ladeira K, Pinho F, et al. Bone metastases: an overview. Oncol Rev. 2017;11(1):321.

4. Hernandez RK, Wade SW, Reich A, et al. Incidence of bone metastases in patients with solid tumors: analysis of oncology electronic medical records in the United States. BMC Cancer. 2018;18(1):44.

5. Böhm P, Huber J. The surgical treatment of bony metastases of the spine and limbs. J Bone Joint Surg Br. 2002;84(4): 521-529.

6. Ortiz Gómez JA. The incidence of vertebral body metastases. Int Orthop. 1995;19(5):309-311.

7. Sohn $\mathrm{S}$, Chung CK. The role of stereotactic radiosurgery in metastasis to the spine. J Korean Neurosurg Soc. 2012;51(1):1-7.

8. Heidecke V, Rainov NG, Burkert W. Results and outcome of neurosurgical treatment for extradural metastases in the cervical spine. Acta Neurochir (Wien). 2003;145(10):873-881.

9. Maccauro G, Spinelli MS, Mauro S, et al. Physiopathology of spine metastasis. Int J Surg Oncol. 2011;2011:107969.

10. Switlyk MD, Kongsgaard U, Skjeldal S, et al. Prognostic factors in patients with symptomatic spinal metastases and normal neurological function. Clin Oncol (R Coll Radiol). 2015; 27(4):213-221.

11. Oliveira MF, Rotta JM, Botelho RV. Survival analysis in patients with metastatic spinal disease: the influence of surgery, histology, clinical and neurologic status. Arq Neuropsiquiatr. 2015;73(4):330-335.

12. Curtin M, Piggott RP, Murphy EP, et al. Spinal metastatic disease: a review of the role of the multidisciplinary team. Orthop Surg. 2017;9(2):145-151.

13. Nater A, Martin AR, Sahgal A, et al. Symptomatic spinal metastasis: a systematic literature review of the preoperative prognostic factors for survival, neurological, functional and quality of life in surgically treated patients and methodological recommendations for prognostic studies. PLoS One. 2017; 12(2):e0171507.

14. Quraishi NA, Rajagopal TS, Manoharan SR, et al. Effect of timing of surgery on neurological outcome and survival in metastatic spinal cord compression. Eur Spine J. 2013;22(6): $1383-1388$.

15. Zibulewsky J. The Emergency Medical Treatment and Active Labor Act (EMTALA): what it is and what it means for physicians. Proc Bayl Univ Med Cent. 2001;14(4):339-346.

16. Froehler MT, Saver JL, Zaidat OO, et al. Interhospital transfer before thrombectomy is associated with delayed treatment and worse outcome in the STRATIS registry (Systematic Evaluation of Patients Treated With Neurothrombectomy Devices for Acute Ischemic Stroke). Circulation. 2017;136(24): 2311-2321.

17. Naval NS, Chang T, Caserta F, et al. Impact of pattern of admission on outcomes after aneurysmal subarachnoid hemorrhage. J Crit Care. 2012;27(5):532.e1-532.e7.

18. Wilde H, Gamblin AS, Reese J, et al. The effect of hospital transfer on patient outcomes after rehabilitation for spinal injury. World Neurosurg. 2020;133:e76-e83.

19. Yelverton S, Rozario N, Matthews BD, Reinke CE. Interhospital transfer for emergency general surgery: An independent predictor of mortality. Am J Surg. 2018;216(4):787-792.

20. Härtl R, Gerber LM, Iacono L, et al. Direct transport within an organized state trauma system reduces mortality in patients with severe traumatic brain injury. J Trauma. 2006; 60(6):1250-1256.

21. Price M, Goodwin JC, De la Garza Ramos R, et al. Gender disparities in clinical presentation, treatment, and outcomes in metastatic spine disease. Cancer Epidemiol. 2021;70: 101856.

22. De la Garza Ramos R, Benton JA, Gelfand Y, et al. Racial disparities in clinical presentation, type of intervention, and in-hospital outcomes of patients with metastatic spine disease: an analysis of 145,809 admissions in the United States. Cancer Epidemiol. 2020;68:101792.

23. Ahmed AK, Goodwin CR, Heravi A, et al. Predicting survival for metastatic spine disease: a comparison of nine scoring systems. Spine J. 2018;18(10):1804-1814.

24. Bouthors C, Prost S, Court C, et al. Outcomes of surgical treatments of spinal metastases: a prospective study. Support Care Cancer. 2020;28(5):2127-2135.

25. Tipsmark LS, Bünger CE, Wang M, et al. Healthcare costs attributable to the treatment of patients with spinal metastases: a cohort study with up to 8 years follow-up. BMC Cancer. 2015;15:354.

26. Durairaj L, Will JG, Torner JC, Doebbeling BN. Prognostic factors for mortality following interhospital transfers to the medical intensive care unit of a tertiary referral center. Crit Care Med. 2003;31(7):1981-1986.

27. Sokol-Hessner L, White AA, Davis KF, et al. Interhospital transfer patients discharged by academic hospitalists and general internists: characteristics and outcomes. J Hosp Med. 2016;11(4):245-250.

28. Kamat S, Chawla S, Rajendram P, et al. An analysis of patients transferred to a tertiary oncological intensive care unit for defined procedures. Am J Crit Care. 2015;24(3): 241-247.

29. Hernandez-Boussard T, Davies S, McDonald K, Wang NE. Interhospital facility transfers in the United States: a nationwide outcomes study. J Patient Saf. 2017;13(4):187-191.

30. Vahidy F, Nguyen C, Albright KC, et al. Transferring patients with intracerebral hemorrhage does not increase in-hospital mortality. PLoS One. 2016;11(7):e0159174.

31. Naval NS, Carhuapoma JR. Impact of pattern of admission on ICH outcomes. Neurocrit Care. 2010;12(2):149-154.

32. Holland CM, Mazur MD, Bisson EF, et al. Trends in patient care for traumatic spinal injuries in the United States: a National Inpatient Sample study of the correlations with patient outcomes from 2001 to 2012. Spine (Phila Pa 1976). 2017; 42(24):1923-1929.

33. De la Garza Ramos R, Goodwin CR, Jain A, et al. Development of a metastatic spinal tumor frailty index (MSTFI) using a nationwide database and its association with inpatient morbidity, mortality, and length of stay after spine surgery. World Neurosurg. 2016;95:548-555.e4.

34. Akezaki Y, Nakata E, Kikuuchi M, Sugihara S. Factors affecting the discharge destination of patients with spinal bone metastases. Ann Rehabil Med. 2020;44(1):69-76.

35. Ethun CG, Bilen MA, Jani AB, et al. Frailty and cancer: implications for oncology surgery, medical oncology, and radiation oncology. CA Cancer J Clin. 2017;67(5):362-377.

36. Karhade AV, Shin JH, Schwab JH. Prognostic models for spinal metastatic disease: evolution of methodologies, limitations, and future opportunities. Ann Transl Med. 2019;7(10): 219.

37. Versteeg AL, van Tol FR, Lehr AM, et al. Malnutrition in 
patients who underwent surgery for spinal metastases. Ann Transl Med. 2019;7(10):213.

38. Abu-Bonsrah N, Goodwin CR, De la Garza-Ramos R, et al. Readmissions after surgical resection of metastatic tumors of the spine at a single institution. World Neurosurg. 2017;101: 695-701.e1.

39. Paulino Pereira NR, Ogink PT, Groot OQ, et al. Complications and reoperations after surgery for 647 patients with spine metastatic disease. Spine J. 2019;19(1):144-156.

\section{Disclosures}

Dr. Erickson: honorarium from DePuy Synthes and fellowship funding from NuVasive. Dr. Sciubba: consultant for Baxter, DePuy Synthes, Medtronic, and Stryker. Dr. Than: consultant for Bioventus and DePuy Synthes Spine; and honoraria from LifeNet Health and DJO. Dr. Karikari: consultant for NuVasive, Globus, and Medtronic; fellowship funding from NuVasive; member of the advisory board for Johnson \& Johnson Adult Deformity Group. Dr. Shaffrey: consultant for Medtronic, NuVasive, and SI Bone; direct stock ownership in NuVasive; royalties from NuVasive; and patent holder with Medtronic, NuVasive, and Zimmer Biomet. Dr. Abd-El-Barr: consultant for Spineology. Dr. Goodwin: honorarium from Johnson \& Johnson; and grants from NIH/ NINDS K12 physician scientist, Food and Drug Administration, and Robert Wood Johnson Harold Amos Medical Faculty Development Program.

\section{Author Contributions}

Conception and design: Goodwin, De la Garza Ramos. Acquisition of data: Goodwin, De la Garza Ramos. Analysis and interpretation of data: Goodwin, De la Garza Ramos, Price. Drafting the article: Goodwin, Park, McCray, Price, Wang, Dalton. Critically revising the article: all authors. Reviewed submitted version of manuscript: Goodwin, De la Garza Ramos. Approved the final version of the manuscript on behalf of all authors: Goodwin. Statistical analysis: De la Garza Ramos. Administrative/technical/ material support: Goodwin. Study supervision: Goodwin.

\section{Correspondence}

C. Rory Goodwin: Duke University Medical Center, Durham, NC. spineresearch@dm.duke.edu. 